\title{
2008 APSA Teaching and Learning Track Summaries
}

\section{Track One: Program Assessment}

\author{
_Michael W. Hail, \\ Morehead State University \\ - Anika Cornelia Leithner, \\ California Polytechnic State University \\ - Paul Fabian Mullen, \\ Armstrong Atlantic State University \\ -William R. Wilkerson, \\ College at Oneonta, SUNY
}

\begin{abstract}
$\mathrm{f}$ the presentations and discussions of the Program Assessment track are any indication, assessment in political science is slowly moving forward. Several presentations provided excellent ideas for instructors and departments seeking to get started and move beyond to take assessment seriously. Presenters and discussants were a mix of veterans and newcomers to assessment from a range of institutions, but the group largely shared an understanding that assessment done well is really a conversation about teaching. Teaching political science is something that we all care about.
\end{abstract}

\section{Walk, Don't Run.}

Many political science departments are now beginning to take assessment seriously. Commitment to assessment tends to follow cycles of attentiveness and focus followed by neglect and ambivalence. Among the myriad reasons for this cycle are factors such as institutional politics, changes in departmental membership, new leadership, fiscal stress, and external demands such as accreditation. But once committed to begin or renew serious assessment efforts, departments often impatiently rush to develop extensive assessment programs.

A functional assessment program will not only provide data for administrators, but will provide feedback about both student-learning outcomes and the assessment process itself, fostering an ongoing conversation about teaching. Assessment takes time, both inside and outside the classroom. Yet if the faculty members assume that they are undertaking assessment for assessment's sake, even small commitments of time will seem onerous. Recurrent themes in panel presentations and discussions included

The 2008 Teaching and Learning Conference (TLC) was held on February 22-24, 2008, in San Jose, California. This year marks the fifth annual TLC. The conference uses the Working Group model, permitting in-depth discussion and debate amongst colleagues on research dealing with the scholarship of teaching and learning. In addition to the 12 Working Groups, there were workshops on various topics. This year there were over 300 registrants, including college and university faculty, graduate students, high school teachers, nonprofit representatives, and others. Michael Brintnall and Kimberly Mealy of APSA offered welcoming remarks. APSA President Dianne Pinderhughes, University of Notre Dame, was the 2008 TLC opening speaker. Dr. Luis Fraga, former APSA council member and associate vice provost of the University of Washington, delivered the keynote address "The Responsibilities of Leadership: Political Science Education for the 21 st Century." The closing program featured short presentations from the chair of the Programming Committee, Sherri Wallace, and from each track moderator. It is our hope that the ideas generated and shared at the TLC will help to foster debate, research, and pedagogical innovations within the discipline.

In addition to a host of sponsors and exhibitors, the 2008 conference also featured two Program Partners, Point Loma Nazarene University and Northeastern University. These schools' contributions have helped support APSA's year-long commitment to teaching and learning in the discipline of political science. For more information on the Partners Program, visit www.apsanet.org/ content_44609.cfm.

APSA would like to thank the following individuals for their service on the 2008 Teaching and Learning Conference Program Committee: Sherri L. Wallace, University of Louisville, chair; Helen Boutrous, Mount Saint Mary's College; Juan Carlos Huerta, Texas A\&M University-Corpus Christi; Russell Mayer, Merrimack College; Cameron G. Thies, University of Missouri-Columbia; and Christopher Van Aller, Winthrop University. These six committee members, along with the following six individuals, served as the 2008 track moderators: Marcus D. Allen, Wheaton College; Mitchell Brown, Auburn University; Tim Meinke, Lynchburg College; Chad Raymond, Elon University; William R. Wilkerson, SUNY Oneonta; and Pamela Zeiser, University of North Florida. For more information on the 2008 TLC or the upcoming 2009 TLC, visit www.apsanet.org/section_ 236.cfm or contact Kim Mealy at kmealy@apsanet.org.

creating assessment programs that provide feedback that tangibly improve a department's program and engage the entire faculty in the assessment process.

Candace Young emphasized that departments should start slowly by using existing data. Once departments develop their own data to augment assessment, they should keep things relatively simple and should focus on topics of interest to faculty. Once fully realized, an assessment regime should include internal and external measures as well as both direct and indirect measures. Keeping assessment relatively simple and focused on faculty interests, by giving faculty ownership of the process, and by framing assessment in such a way that it blends improvement and accountability, increases chances of successful implementation.

\section{Many Strategies and Techniques Are Available for Departments}

We reviewed various approaches to getting started, but the importance of selecting an approach and actually getting started was a sustained point throughout the conference. A common theme was that any strategy has to be tailored to a department's specific circumstances and needs. There is no onesize-fits-all approach. Michelle Deardorff and Paul Folger suggested that the 
makeup and culture of a department should determine the appropriate approach. A "mission-based" model, integrating assessment into the program right from the start based on established learning objectives and a curriculum designed to meet them, might be best for smaller departments with a large number of untenured faculty and a greater focus on teaching, because they are potentially more receptive to such a comprehensive approach. In contrast, a grassroots "question-based" model that relies on a non-threatening, incremental approachbeginning with classroom assessment and branching out from there-might be better received in larger departments with a greater research focus, in which resistance to assessment might be higher. Vicki Golich emphasized the need to align program assessment across other levels of institutional assessment at the university.

Two presentations illustrated individual department assessment plans. Each used portfolios as an alternative to exit interviews and standardized tests. Alexandra Cole and Jennifer De Maio noted that portfolios can set appropriate criteria for the successful completion of a degree as well as allow for measuring students' progress throughout the program. Surprisingly, faculty in the department did not perceive portfolios as excessive amounts of work. Shala Mills and Bryan Bennett advocated the use of writing portfolios to assess students' writing skills throughout the program. The focus on writing has had unexpected benefits for students and faculty at their university. The department now has clearer goals and expectations for their program and for student work. Students better understand these expectations and the connections between courses. By having students manage their own portfolios, students have been encouraged to think about their career goals.

\section{Learning about Our Students}

Beginning to take assessment seriously has encouraged political scientists to assess programs and to consider how students learn and what they know. For example, Anika Leithner raised the question of whether students' individual learning styles correlate with certain "testing styles," arguing that the way students learn impacts how well they do on certain exam formats; thus questioning the reliability of some of our assessment techniques. Kevin Jeffries asked what our students know by using standardized exams offered to high school students. Introductory courses, he argued, must ensure that students can participate in the deliberation necessary for effective citizenship and that assessment instruments ought to focus on the knowledge that allows for such citizenship. At the very least we could benefit from an expansion of the conversation on assessment to the high school and community college level, rather than making assumptions about students' prior knowledge.

Other presentations focused on classroom assessment as an excellent starting point for implementing higher education assessment, because faculty members are used to it and less likely to resist new techniques, especially if it improves student performance. Ruth Ediger focused on the usefulness of extra-textbook materials, suggesting that such materials - if used properly by the instructor-do indeed benefit student learning, thus encouraging us to think beyond the traditional lecture/ textbook approach to teaching. Phillip Pollock, Bruce Wilson, and Kerstin Hamman illustrated that online courses can be as effective as traditional courses in meeting certain learning objectives, and even better in some cases. In addition, the built-in assessment tools in many online systems allow for the efficient collection of large amounts of data, thus benefiting departmental assessment in the long run. Christine Nemacheck illustrated the benefits of an integrated internship program as an extension of traditional student learning. By combining traditional classroom instruction, the internship experience, and independent student research, the potential for learning with such a program is tremendous.

\section{Resources Are Increasing for Assessment in the Discipline.}

Perhaps the most important lesson was that assessment is a long-term effort that requires a department culture of faculty engagement. Since external assessment requirements are certain to continue, more resources need to be developed to assist departments and individual faculty members in these efforts. The discipline is just beginning to catch up in this regard. The papers presented at this conference, both in the Program Assessment track and other tracks, serve as excellent resources. The Journal of Political Science Education publishes research that will be of use. Finally, Michele Deardorff, Kerstin Hamann, and John Ishiyama have recently edited The APSA Guide to Assessment in Political Science.

\section{Track Two: Graduate Education and Professional Development}

\author{
-W. T. Casey, \\ University of Texas at Dallas \\ -Sharon Jones, \\ Columbia College \\ -Elizabeth Lowham, \\ California Polytechnic State University \\ -Cameron G. Thies, \\ University of Iowa
}

$\mathrm{H}$ ow well do we prepare our graduate students for the diverse careers they pursue in teaching, research, and outside of academia? This is the second time Graduate Education has been a track in the TLC, and this year we have also incorporated topics related to professional development. ${ }^{1}$ Despite the diversity of our presentations, we arrived at a unifying theme for our track: we must prepare graduate students for the multiple arenas they will enter into after graduation. We discussed at length how most of our graduate students seek something other than the traditional, research-oriented model of graduate education that we experienced. They seek a graduate experience that is civically engaged, prepares them for teaching in addition to research, and is perhaps more connected to disciplines outside of political science. Either we provide graduate students a framework of knowledge consistent with these demands or they will be left to develop these skills through trial and error alone. In support of this goal, we urge systemic change to our professional institutions that will value and reward a more holistic approach to graduate education and professional development. Elements of such change can be found in the variety of presentations contained in our track.

\section{Graduate Education}

What do we teach our students about teaching? The papers in our track that investigated educator training in graduate programs demonstrated that we need to consider the processes and types of experiences that produce good teachers. In a comparison of universities within the European Union, Eszter Simon and Gabiela Pleschova find that graduate students experience vastly different teacher training programs, from no available training to practical courses in course and classroom management. They conclude that "teaching is an integral and important part" of an academic career, but attaining the level of teaching effectiveness needed for higher education is 